\title{
PENGEMBANGAN MODEL PEMBELAJARAN AKTIVITAS JASMANI BAGI ANAK SD SLB TUNANETRA DI KOTA SINGKAWANG
}

\author{
Zainal Arifin", Marhadi Saputro ${ }^{2}$, Rubiyatno ${ }^{3}$, Whalsen Duli Agus Lauh ${ }^{4}$ \\ ${ }^{1,4}$ Program Studi Penjaskesrek, IKIP PGRI Pontianak, Jln. Ampera No.88 Pontianak \\ ${ }^{2}$ Program Studi P. Matematika, IKIP PGRI Pontianak, Jln. Ampera No. 88 Pontianak \\ ${ }^{3}$ Program Studi Pendidikan Kepelatihan Olahraga, Universitas Tanjungpura Pontianak \\ Jln. A. Yani 2 Pontianak \\ 1e-mail: zai_nal@yahoo.co.id
}

\begin{abstract}
Abstrak
Penelitian ini bertujuan mengembangkan model pembelajaran aktivitas jasmani bagi siswa SD SLB Tunanetra di kota Singkawang. Berdasarkan wawancara dan observasi disimpulkan bahwa pengembangan pembelajaran aktivitas jasmani bagi siswa SD SLB Tunanetra di kota Singkawang dinilai masih kurang variatif dan masih monoton. Kurangnya model permainan dalam pengembangan pembelajaran aktivitas jasmani tersebut membuat peneliti tertarik mengembangkan pembelajaran kinestetik untuk meningkatkan keaktifan siswa khususnya pada aspek jasmani bagi siswa SD SLB Tunanetra. Metode penelitian yang digunakan yaitu penelitian pengembangan ( $R$ \& D) Instrumen pengumpulan data yang digunakan yaitu: (1) Pedoman wawancara, (2) Skala nilai, (3) Pedoman observasi permainan. Hasil penelitian ini berupa buku panduan aktivitas pembelajaran jasmani untuk siswa SD SLB Tunanetra yang berisikan empat jenis permainan, yaitu: (1) permainan tali penolong, (2) permainan mencari nada, (3) permainan halau bola, (4) permainan bowling ceriadan (5) permainan voli bawah net. Permainan-permainan tersebut sudah melalui proses validasi oleh guru dan pakar dibidangnya.
\end{abstract}

Kata Kunci: Aktivitas, jasmani, tunanetra

\begin{abstract}
This study aims to develop a model of learning physical activity for elementary school students in Tunanetra SLB in Singkawang. Based on interviews and observations it was concluded that the development of physical activity learning for elementary school students in the Blind Tunanetra elementary school in Singkawang was considered to be less varied and still monotonous. The lack of game models in the development of physical activity learning makes researchers interested in developing kinesthetic learning to improve student activity, especially in physical aspects for students with visual impairment. The research method used is the research development $(R \& D)$ Data collection instruments used are: (1) Interview guidelines, (2) Scales of value, (3) Game observation guidelines. The results of this study are in the form of a physical learning activity manual for elementary school students with visual impairment which contains four types of games, namely: (1) a game of rope, (2) a game of looking for tones, (3) a game of ball bearing, (4) a game of bowling cherry (( 5) volleyball net game. These games have been through the validation process by teachers and experts in their fields.
\end{abstract}

Keywords: Activity, physical, visual impairment. 


\section{PENDAHULUAN}

Pendidikan jasmani merupakan suatu proses seseorang sebagai individu maupun anggota masyarakat yang dilakukan secara sadar dan sistematik melalui berbagai kegiatan dalam rangka memperoleh kemampuan dan keterampilan jasmani, pertumbuhan, kecerdasan, dan pembentukan watak. Pendidikan jasmani pada hakikatnya adalah proses pendidikan yang memanfaatkan aktivitas fisik untuk menghasilkan perubahan holistic dalam kualitas individu, baik dalam hal fisik, mental, serta emosional. Pendidikan jasmani dan olahraga merupakan laboratorium bagi pengalaman manusia, karena dalam pendidikan jasmani menyediakan kesempatan untuk memperlihatkan mengembangan karakter. Pengajaran etika dalam pendidikan jasmani biasanya dengan contoh atau perilaku. Pengajar tidak baik berkata kepada muridnya untuk memperlakukan orang lain secara adil kalau dia tidak memperlakukan muridnya secara adil. Selain dari pada itu pendidikan jasmani dan olahraga begitu kaya akan pengalaman emosional. Aneka macam emosi terlibat di dalamnya. Kegiatan pendidikan jasmani dan olahraga yang berakar pada permainan, ketrampilan dan ketangkasan memerlukan pengerahan energi untuk menghasilkan yang terbaik (Rosdiani, 2012: 13). Fokus pendidikan jasmani pada pengaruh perkembangan fisik terhadap wilayah pertumbuhan dan perkembangan aspek lain dari manusia itulah yang menjadikan unik. Tidak ada bidang tunggal lainnya seperti pendidikan jasmani yang berkaitan dengan perkembangan total manusia. Pada dasarnya pendidikan jasmani, dengan memanfaatkan alat gerak manusia, dapat membuat aspek mental dan moral pun ikut berkembang. Dalam konteks pendidikan inklusif, pelayanan pendidikan jasmani diberikan kepada semua anak dengan karakteristik yang berbeda-beda termasuk Anak Berkebutuhan Khusus (Abdullah, 2011: 19).

Di sekolah yang menyelenggarakan pendidikan inklusif terdapat peserta didik yang mengalami beranekaragam hambatan, baik hambatan penglihatan, pendengaran, motorik, komunikasi, perhatian, emosi, perilaku, sosial, dan sebagainya. Mereka berhak atas pendidikan jasmani yang dapat mengakomodasi hambatan dan kebutuhan yang mereka miliki. Oleh karena itu, pembelajaran pendidikan jasmani menjadi lebih kompleks bagi guru pendidikan jasmani dalam 
mengupayakan agar semua kebutuhan anak akan gerak dapat terpenuhi dan dapat meningkatkan potensi yang dimilikinya secara optimal. Pada kenyataannya tidak semua $\mathrm{ABK}$ mendapatkan layanan pendidikan jasmani sesuai dengan kebutuhan atau hambatan yang dimilikinya, karena tidak semua guru pendidikan jasmani memahami dan mengetahui layanan yang harus diberikan kepada ABK.

Kebutuhan gerak ABK lebih besar dari pada siswa lainnya, karena ABK mengalami hambatan dalam merespon rangsangan yang diberikan lingkungan untuk melakukan gerak, meniru gerak dan bahkan ada yang memang fisiknya terganggu sehingga ia tidak dapat melakukan gerakan yang terarah dengan benar Hal ini terjadi karena mereka memiliki masalah dalam sensorisnya, motoriknya, belajarnya, dan tingkah lakunya yang dapat menghambat perkembangan fisik siswa tersebut hal ini sejalan dengan hasil penelitian Suroso (2013: 25) Dalam karyanya yang berjudul "Problematika Pembelajaran Pendidikan Jasmani bagi Tunanetra di Sekolah Umum" yang menyatakan bahwa guru pendidikan jasmani tidak memahami pelaksanaan pendidikan jasmani adaptif, sehingga pembelajaran yang diberikan tidak sesuai dengan kebutuhan dan hambatan yang dimiliki oleh ABK.

Secara umum tuna netra merupakan keadaan dimana kondisi dari individu yang memiliki keterbatasan dalam melihat alam sekitar. Menurut Hakim (2013: 15) mereka yang memiliki kombinasi ketajaman penglihatan hamper kurang dari 0,3 (60/200) atau mereka yang mempunyai tingkat kelainan fungsi penglihatan yang lainnya lebih tinggi yaitu mereka yang tidak mungkin atau berkesulitan secara signifikan untuk membaca tulisan ilustrasi awas meskipun dengan mempergunakan alat bantu kaca pembesar. Pengertian tuna netra tidak saja mereka yang buta, tetapi mencakup juga mereka yang mampu melihat tetapi terbatas sekali dan kurang dapat dimanfaatkan untuk kepentingan hidup seharihari terutama dalam belajar. Jadi, anak-anak dengan kondisi penglihatan yang termasuk "setengah melihat", "low vision" atau rabun adalah bagian dari kelompok anak tuna nerta (Gunawan, 2014: 34).

Di kota Singkawang terdapat sekolah luar biasa yang tersebar dalam beberapa kecamatan baik itu yang berstatus negeri maupun swasta. hal ini 
ditujukan untuk mengakomodir para siswa yang memiliki kebutuhan khusus baik itu tunanetra, tunarungu, dan tunagrahita. Berdasarkan observasi dan wawancara dengan guru pendidikan jasmani di beberapa SDLB mereka menyatakan mengajar di SLB merupakan tantangan bagi mereka, karena sangat dibutuhkan kesabaran dalam mendidik anak-anak berkebutuhan khusus. Ditambah lagi anak berkebutuhan khusus juga memiliki kebutuhan gerak yang besar. Hal ini sangat dituntut peran guru penjas dalam memberikan metode pembelajaran yang dapat mengakomodir kebutuhan gerak khususnya siswa tunanetra. Selama ini model pembelajaran penjas untuk anak tunanetra dinilai masih kurang variatif dan masih monoton dengan permainan seperti sekarang ini. Kurangnya model permainan dan model pembelajaran penjas tersebut membuat peneliti tertarik untuk mengembangkan atau membuat berbagai model pembelajaran atau permainan berbasis kinestetik untuk anak tunanetra. Sehingga diharapkan dari penelitian ini terciptalah sebuah model pembelajaran yang tertuang dalam sebuah buku yang diharapkan sangat bermanfaat bagi guru penjas yang ada di SDLB khususnya untuk tunanetra sebagai referensi dalam memberikan pembelajaran gerak dalam rangka memenuhi kebutuhan gerak siswa tunanetra.

\section{METODE}

Prosedur pengembangan dalam penelitian ini sejalan dengan langkahlangkah penelitian pengembangan menurut Borg \& Gall. Borg \& Gall (1983: 775) mengemukakan bahwa dalam melakukan penelitian pengembangan terdapat 10 langkah yang harus ditempuh, namun kemudian diadaptasi menjadi 7 tahapan yaitu : (1) Pengumpulan Informasi di Lapangan, (2) Melakukan Analisis Terhadap Informasi yang Telah Dikumpulkan, (3) Mengembangkan Produk Awal (Draf Model), (4) Validasi Ahli dan Revisi, (5) Uji Coba Lapangan Skala Kecil dan Revisi,(6) Uji Coba Lapangan Skala Besar dan Revisi, (7) Pembuatan Produk Final. Adapun sekolah yang digunakan sebagai uji coba dalam penelitian ini yaitu SLB N Singkawang dan SLB dan SLB Dharma Miranti Singkawang.

Teknik pengumpulan data yang digunakan yaitu teknik komunikasi langsung dengan menggunakan instrumen wawancara sebagai alat pengumpul 
data dan skala nilai. Skala nilai ini digunakan untuk menilai kelayakan model permainan yang dikembangkan sebelum pelaksanaan uji coba skala kecil. Setelah para ahli menilai bahwa model permainan sudah sesuai dengan unsur-unsur dalam skala nilai, model permainan baru dapat diujicobakan dalam uji coba skala kecil. Dalam skala nilai, variabel atau tujuan penelitian diklasifikasikan secara rinci menjadi gejala-gejala dengan unsur-unsurnya.

Teknik analisis data yang digunakan dalam penelitian ini adalah analisis data deskriptif. Ada dua macam teknik analisis data yaitu kuantitatif dan kualitatif. Analisis data kuantitatif dilakukan untuk menganalisis data hasil observasi para ahli dan guru penjas terhadap kualitas draf model yang disusun yang dianalisis oleh para pakar dan guru penjas sebelum pelaksanaan uji coba di lapangan (Purwanti, 2011: 23). Sedangkan analisis data kualitatif dilakukan terhadap data hasil observasi para ahli dan guru penjas dalam memberikan saran ataupun masukan serta revisi terhadap model yang disusun terutama dalam tahap ujicoba di lapangan baik dalam skala kecil ataupun skala luas. Untuk data hasil observasi para ahli materi terhadap model permainan, keefektifan model permainan, dan guru pelaku uji coba terdapat dua jenis nilai. Hasil observasi "ya" mendapat nilai satu (1) dan hasil observasi "tidak" mendapat nilai nol (0). Hasil penilaian terhadap item-item observasi dijumlahkan, lalu total nilainya dikonversikan untuk mengetahui kategorinya. Pengkonversian nilai dilakukan dengan mengikuti standar Penilaian Acuan Patokan (Komarudin, 2016: 23).

\section{HASIL DAN PEMBAHASAN}

Hasil penilaian para ahli dan guru di lapangan terhadap model pembelajaran jasmani untuk meningkatkan kemampuan indra peraba dan pendengaran. adapun aspek yang dinilai oleh para ahli meliputi meliputi (1) observasi terhadap model permainan, (2) observasi terhadap aspek jasmani yang muncul dalam pembelajaran tersebut. 


\section{Permainan Tali Penolong}

Tabel 1 menyajikan data skala besar ahli terhadap aspek jasmani yang muncul dalam permainan tali penolong.

Tabel 1 Data Skala Besar Ahli Terhadap Aspek Jasmani yang Muncul Dalam Permainan Tali Penolong

\begin{tabular}{|c|c|c|c|c|c|c|c|c|}
\hline \multirow{2}{*}{ Ahli Materi } & \multicolumn{7}{|c|}{ Aspek Penilaian } & \multirow[t]{2}{*}{ Skor } \\
\hline & 1 & 2 & 3 & 4 & 5 & 6 & 7 & \\
\hline Pakar 1 & 1 & 1 & 1 & 1 & 1 & 1 & 1 & 7 \\
\hline Pakar 2 & 1 & 1 & 1 & 1 & 1 & 1 & 1 & 7 \\
\hline Guru 1 & 1 & 1 & 1 & 1 & 1 & 1 & 1 & 7 \\
\hline Guru 2 & 1 & 1 & 1 & 1 & 1 & 1 & 1 & 7 \\
\hline
\end{tabular}

Keterangan:

Nilai Maksimal $=28$

A: Nilai yang diperoleh, B: Nilai maksimal

$\mathrm{A} / \mathrm{B}$ X $100 \%$

$28 / 28 \times 100=100 \%=$ Kategori sangat baik

Permainan tali penolong ini di desain untuk mengakomodir siswa tunanetra dalam mendukung aktivitas geraknya. dalam hal ini guru membentangkan tali yang di ikatkan pada dua tiang, kemudian siswa berjalan dengan memegang tali tersebut. Aktivitas berjalan menggunakan tali penolong bisa divariasikan mulai dari berjalan maju, mundur hingga kesamping. Hal ini bertujuan selain untuk melatih aktivitas jasmani siswa, juga diperuntukan agar siswa penyandang tunanetra tersebut memahami konsep arah, sehingga mempermudah aktivitasnya sehari-hari.

Berdasarkan penilaian uji coba skala besar dari para ahli terhadap aspek jasmani khususnya indra peraba dan pendengaran pada permaian tali penolong. terlihat bahwa hasil yang didapat telah menunjukan nilai maksimal yaitu $100 \%$ yang berada dalam kategori sangat baik. Dari hasil tersebut dapat disimpulkan model permainan ini sangat baik untuk meningkatkan sensitifitas indra peraba dan pendengaran bagi siswa tunanetra.

\section{Permainan Mencari Nada}

Tabel 2 menyajikan data skala besar ahli terhadap aspek jasmani yang muncul dalam permainan mencari nada. 
Tabel 2. Data Skala Besar Ahli Terhadap Aspek Jasmani Yang Muncul Dalam Permainan Mencari Nada

\begin{tabular}{|c|c|c|c|c|c|c|c|c|}
\hline \multirow{2}{*}{ Ahli Materi } & \multicolumn{7}{|c|}{ Aspek Penilaian } & \multirow[t]{2}{*}{ Skor } \\
\hline & 1 & 2 & 3 & 4 & 5 & 6 & 7 & \\
\hline Pakar 1 & 1 & 1 & 1 & 1 & 1 & 1 & 1 & 7 \\
\hline Pakar 2 & 1 & 1 & 1 & 1 & 1 & 1 & 1 & 7 \\
\hline Guru 1 & 1 & 1 & 1 & 1 & 1 & 1 & 1 & 7 \\
\hline Guru 2 & 1 & 1 & 1 & 1 & 1 & 1 & 1 & 7 \\
\hline
\end{tabular}

Keterangan:

Nilai Maksimal $=28$

A: Nilai yang diperoleh, B: Nilai maksimal

A/B X $100 \%$

$28 / 28 \times 100=100 \%=$ Kategori sangat baik

Permainan mencari nada merupakan salah satu permainan yang dikembangkan dengan mengkolaborasikan alat-alat musik yang berbeda. Hal ini agar menarik minat siswa dalam mengikuti aktivitas jasmani serta memberikan pemahaman tentang jenis-jenis suara alat musik yang berbeda. Dalam permainan ini siswa di intruksikan untuk mencari suara musik dan berjalan kearah sumber suara yang dihasilkan oleh setiap jenis alat musik tersebut, permainan ini dapat merangsang sesitifitas indera pendengaran dan berguna untuk memahami konsep arah.

Berdasarkan penilaian uji coba skala besar dari para ahli terhadap aspek jasmani khususnya indra peraba dan pendengaran pada permaian mencari nada. terlihat bahwa hasil yang didapat telah menunjukan nilai maksimal yaitu $100 \%$ yang berada dalam kategori sangat baik. Permainan ini dapat meningkatkan keaktifan siswa dalam aktivitas jasmani sekaligus dapat merangsang sensitifitas indra peraba dan pendengaran. Permainan ini menggunakan berbagai macam jenis nada serta ditentukan pula jenis gerak pada setiap nada berbunyi, sehingga siswa dapat berkompetisi antara satu dan lainnya dalam merespon nada-nada tersebut.

\section{Permainan Halau Bola}

Tabel 3 menyajikan data skala besar ahli terhadap aspek jasmani yang muncul dalam permainan halau bola. 
Tabel 3 Menyajikan Data Skala Besar Ahli Terhadap Aspek Jasmani Yang Muncul Dalam Permainan Halau Bola

\begin{tabular}{|c|c|c|c|c|c|c|c|c|}
\hline \multirow{2}{*}{ Ahli Materi } & \multicolumn{7}{|c|}{ Aspek Penilaian } & \multirow[t]{2}{*}{ Skor } \\
\hline & 1 & 2 & 3 & 4 & 5 & 6 & 7 & \\
\hline Pakar 1 & 1 & 1 & 1 & 1 & 1 & 1 & 1 & 7 \\
\hline Pakar 2 & 1 & 1 & 1 & 1 & 1 & 1 & 1 & 7 \\
\hline Guru 1 & 1 & 1 & 1 & 1 & 1 & 1 & 1 & 7 \\
\hline Guru 2 & 1 & 1 & 1 & 1 & 1 & 1 & 1 & 7 \\
\hline
\end{tabular}

Keterangan:

Nilai Maksimal $=28$

A: Nilai yang diperoleh, B: Nilai maksimal

$\mathrm{A} / \mathrm{B} \times 100 \%$

$28 / 28 \times 100=100 \%=$ Kategori sangat baik

Permainan halau bola dikembangkan dengan tujuan untuk melatih respon tubuh serta kecepatan reaksi dari siswa penyandang tunanetra tersebut. Permainan ini dapat dimainkan dengan menggunak alat berupa bola yang diberikan suara seperti kerincing. Kemudian guru menggelindingkan bola tersebut ke arah siswa yang sudah siap berjajar untuk menghalau bola tersebut. Apabila ada siswa yang mampu menghalau bola tersebut maka siswa tersebut yang dinyatakan sebagai pemenang

Berdasarkan penilaian uji coba skala besar dari para ahli terhadap aspek jasmani khususnya indra peraba dan pendengaran pada permaian mencari nada. Setelah dilakukan revisi pada saat uji coba skala kecil. Terlihat permainan ini sangat cocok bagi siswa tunantera dalam mengasah ketrampilan geraknya. Permainan ini membutuhkan feeling pada saat mendengar suara bola lalu siswa berlomba mneyentuhkan tangannya pada bola tersebut.

\section{Permainan Bowling Ceria}

Tabel 4 menyajikan data skala besar ahli terhadap aspek jasmani yang muncul dalam permainan bowling ceria. 
Tabel 4 Data Skala Besar Ahli Terhadap Aspek Jasmani Yang Muncul Dalam Permainan Bowling Ceria

\begin{tabular}{|c|c|c|c|c|c|c|c|c|}
\hline \multirow{2}{*}{ Ahli Materi } & \multicolumn{7}{|c|}{ Aspek Penilaian } & \multirow[t]{2}{*}{ Skor } \\
\hline & 1 & 2 & 3 & 4 & 5 & 6 & 7 & \\
\hline Pakar 1 & 1 & 1 & 1 & 1 & 1 & 1 & 1 & 7 \\
\hline Pakar 2 & 1 & 1 & 1 & 1 & 1 & 1 & 1 & 7 \\
\hline Guru 1 & 1 & 1 & 1 & 1 & 1 & 1 & 1 & 7 \\
\hline Guru 2 & 1 & 1 & 1 & 1 & 1 & 1 & 1 & 7 \\
\hline
\end{tabular}

Keterangan:

Nilai Maksimal $=28$

A: Nilai yang diperoleh, B: Nilai maksimal

A/B X $100 \%$

$28 / 28 \times 100=100 \%=$ Kategori sangat baik

Permainan bowling ceria ini dikembangkan dengan tujuan untuk melatih unsur ketepatan dan akurasi siswa penyandang tunanetra. Permainan cukup menarik untuk dimainkan karena siswa masing-masing mendapatkan kesempatan untuk berusaha menggelindingkan bola ke depan atau kearah target berupa botol yang sudah disiapkan oleh guru, pemenang dalam permainan ini adalah siswa yang paling banyak menjatuhkan botol atau target tersebut

Berdasarkan penilaian uji coba skala besar dari para ahli terhadap aspek jasmani khususnya indra peraba dan pendengaran pada permaian bowling ceria. terlihat bahwa hasil yang didapat telah menunjukan nilai maksimal yaitu $100 \%$ yang berada dalam kategori sangat baik. Dari hasil tersebut dapat disimpulkan model permainan ini sangat baik untuk meningkatkan sensitifitas indra peraba dan pendengaran bagi siswa tunanetra.

\section{Permainan Voli Bawah Net}

Tabel 5 menyajikan data skala besar ahli terhadap aspek jasmani yang muncul dalam permainan voli bawah net. 
Tabel 5 Menyajikan Data Skala Besar Ahli Terhadap Aspek Jasmani Yang Muncul Dalam Permainan Voli Bawah Net

\begin{tabular}{|c|c|c|c|c|c|c|c|c|}
\hline \multirow{2}{*}{ Ahli Materi } & \multicolumn{7}{|c|}{ Aspek Penilaian } & \multirow{2}{*}{ Skor } \\
\hline & 1 & 2 & 3 & 4 & 5 & 6 & 7 & \\
\hline Pakar 1 & 1 & 1 & 1 & 1 & 1 & 1 & 1 & 7 \\
\hline Pakar 2 & 1 & 1 & 1 & 1 & 1 & 1 & 1 & 7 \\
\hline Guru 1 & 1 & 1 & 1 & 1 & 1 & 1 & 1 & 7 \\
\hline Guru 2 & 1 & 1 & 1 & 1 & 1 & 1 & 1 & 7 \\
\hline
\end{tabular}

Keterangan:

Nilai Maksimal $=28$

A: Nilai yang diperoleh, B: Nilai maksimal

$\mathrm{A} / \mathrm{B} \times 100 \%$

$28 / 28 \times 100=100 \%=$ Kategori sangat baik

Permainan terakhir yang dikembangkan yaitu permainan voli bawah net. Permainan ini membutuhkan agresivitas yang ckup tinggi dibandingkan permainan lain, karena dalam permainan ini terdapat unsur serangan dan aktivitas bertahan, untuk itu dalam permainan ini sangat dituntut felling yang baik sehingga setiap pemain dapat mengetahui arah bola serta dapat melakukan serangan ke tim lawan

Berdasarkan penilaian uji coba skala besar dari para ahli terhadap aspek jasmani khususnya indra peraba dan pendengaran pada permaian voli bawah net. Permainan ini dapat meningkatkan keaktifan siswa dalam aktivitas jasmani sekaligus dapat merangsang sensitifitas indra peraba dan pendengaran. Permainan ini menuntut kesigapan siswa dalam merespon rangsangan berupa suara yang berasal dari pukulan bola, serta siswa dituntut memiliki feeling dalam menghalau bola sehingga lawan sulit untuk mendapat poin saat melakukan pukulan atau serangan.

\section{SIMPULAN}

Pendidikan merupakan hak bagi setiap anak di indonesia tidak terkecuali anak-anak yang mengalami disabilitas, mereka memilik hak yang sama atas pendidikan tersebut. Keterbatasan yang dialami kadang menghambat mereka 
untuk bersosialisisasi layaknya anak normal lainnya. Untuk itu selaku pendidik harus perduli dengan keterbatasan tersebut. Seorang pendidik harus mampu memfasilitasi siswa-siswa yang mengalami disabilitas tersebut untuk menggali potensi-potensi yang dimilik. Dalam aktivitas gerak khususnya bagi tunanetra harus di buat bentuk-bentuk aktivitas yang mampu membuat mereka aktif secara jasmani yang diharapkan juga dapat meningkatkan rasa percaya diri bagi siswa penyandang disabilitas tersebut. Dalam penelitian ini dikembangkan beberapa model permainan khsususnya bagi penyandang tunanetra. Peneliti menggunakan beberapa tahapan dalam pengembangan ini sesuai dengan teori yang sudah ada. Sehingga dapat disimpulkan bahwa model permainan yang dikembangkan tersebut sangat sesuai bagi aktivitas jasmani siswa penyandang tunanetra karena dalam substansi permainan tersebut selain terdapat aspek biomotor juga melatih sensitivitas indra pendengaran dan perabaan sehingga sangat cocok untuk diterapkan dalam rangka menambah variasi dalam pembelajaran gerak bagi penyandang tunanetra.

\section{DAFTAR PUSTAKA}

Abdullah, dkk. (2011). Coaching athletes with disabilities-guidelines and principles in training methodology. Jurnal Media Ilmu Keolahragaan Indonesia, 1(1), 68-75.

Borg, W. R. \& Gall, M. D. (1983). Educational research (an Introduciton), $4^{\text {th }}$ ed. New York: Longman.

Gunawan, F. (2014). Survei pelaksanaan pembelajaran pendidikan jasmani adaptif sekolah dasar luar biasa se-kabupaten Gunungkidul. Journal of Physical Education, Sport, Health and Recreation, 3(2), 916-921.

Hakim, R. A. (2013). Pengaruh usia dan latihan keseimbangan terhadap kemampuan motorik kasar kelas bawah mampu didik sekolah luar biasa. Jornal Of Physical Education and Sports, 2, 201-204.

Komarudin. 2016. Penilaian hasil belajar pendidikan jasmani dan olahraga. Bandung: PT Remaja Rosdakarya.

Rosdiani, D. (2012). Model pembelajaran langsung dalam pendidikan jasmani dan kesehatan. Bandung: Alfabeta.

Suroso, A. (2013). Pengaruh model pembelajaran dan motorik dasar terhadap hasil belajar Penjasorkes bagi peserta sekolah dasar kelas awal. Journal of Physical Education and Sport, 2, 187-192. 